\title{
THE EFFECTS OF BROILER FEED FORMS ON METABOLIC AND SKELETAL DISORDERS
}

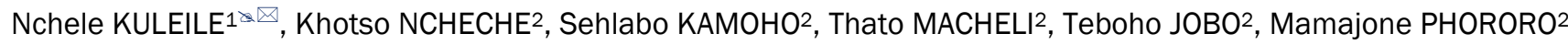 \\ ${ }^{1}$ Lesotho Agricultural College, Private Bag A4, Maseru 100, Lesotho \\ ${ }^{2}$ National University of Lesotho, Department of Animal Science, P.O. Roma 180, Lesotho \\ Email: nchelekuleile@gmail.com \\ supporting Information
}

ABSTRACT: A completely randomized study was conducted at the National University of Lesotho farm (altitude 1650 meters) to address the high incidence of metabolic and skeletal disorders in broiler chickens. The incidence of ascites also increases significantly at altitudes greater than 1300 meters above sea level, presumably because of the low oxygen partial pressure. The ascites incidences are very high in Lesotho during the cold winter months, accounting for more than fifty percent of the total mortality. The main objective of the current study was to assess the effect of different feed forms on the occurrence and control of metabolic disorders in broilers. A total of 200 day-old Ross 308 chicks were randomly distributed into two dietary treatments made up of two broiler feed forms namely mash and pelleted diet replicated four times with twentyfive birds per replicate. The two dietary treatments had similar nutritive value across all feeding phases with exception of feed form. Chicks were housed in a well-ventilated house where treatment diets and water were offered on ad libitum basis. Data collection was done on weekly basis for production parameters such as feed intake, feed conversion ratio, live weight and growth rate while mortality, signs of ascites, lameness and Sudden Death Syndrome (SDS) data were collected daily. All dead birds were examined for the signs of ascites by presence or accumulation of fluids in the abdominal cavity. The findings of the current study indicated that dietary treatment had a significant $(P<0.05)$ influence on all production parameters namely feed intake, live weight, growth rate, feed conversion ratio and mortality rate. The dietary treatment also had a significant effect on incidences of ascites and lameness in broiler chickens whereby birds offered diet in the form of pellets had better production performance and higher incidences of the ascites, lameness and mortality than birds fed diet in mash form. On the other hand the dietary treatments did not have a significant $(P>0.05)$ effect on SDS. However, there were more incidences of SDS in birds offered pelleted diets than mash diet. Birds fed mash diet had fewer incidences because they were experiencing moderate growth rates compared to birds fed pelleted diet with fast growth rates. Birds offered mash spend more time consuming their feed compared to birds fed pellets and therefore, expend more energy in this process resulting in lower feed conversion efficiency. It was evident from the results that diet in mash form can be used to control the incidences of metabolic disorder by reducing growth rates of broilers.

Keywords: Form, Ascites, Mash, Pellets, Growth Mortality

\section{INTRODUCTION}

Farmers in Lesotho suffer a huge financial loss during production phase of their broiler chickens as a result of high incidences of metabolic and skeletal disorders that leads to high mortality of chicks and condemnation of carcasses later (Amini et al., 2015). The incidence is common during the cold winter months as is influenced by cold temperatures and poor ventilation methods (Huchzermeyer et al., 1989) and this had led to the seasonality of broiler production in Lesotho as a result (Kuleile and Molapo, 2019). Most of the farmers especially those in the highlands of Lesotho do not produce any broiler during cold months fearing the high mortality rate. Broilers suffer from two forms of heart failure; ascites and sudden death syndrome (SDS) (Maxwell and Robertson, 1998). Ascites and SDS are relatively common and are likely to be due to the fact that the broilers' fast growth requires high levels of oxygen to support metabolic demands (SCAHAW, 2000). Ascites is a common rapid-growth-related problem in broiler chickens grown at high altitude where the partial pressure of oxygen is low and is marginally adequate to support the growth performance and ascites-related variables and it can be recognized by the fluid accumulation in abdominal cavity (Saffar and Khajali, 2010). SDS is an acute heart failure disease that affects mainly male fast-growing chickens which seem to be in good condition. It is characterized by the sudden death of well-nourished broiler chickens after abrupt and brief flapping of their wings (Saki and Hemati, 2011). Death usually occurs within 1-2 minutes with the birds lying on their backs with outstretched wings (Afolayan et al., 2016). Leg problems seen in the absence of infectious agents are often the result of fast early growth and thus can be related to metabolic diseases (Kumari et al., 2016). Poultry metabolic diseases occur primarily in two body systems being cardiovascular disorders, which in broiler chickens are responsible for a major portion of the flock mortality; secondly musculoskeletal disorders, which account for less mortality, but slow down growth (thereby reducing profit), and cause 
lameness, which remains a major welfare concern (Julian, 2005). Lameness is associated with heavy, fast-growing broilers and is of serious welfare concern due to an inability of lame birds to access resources, limited behavioral expression, and pain (Nicol et al. 2017). Lameness can take many forms. It can be infectious, arise due to developmental bone deformities or be degenerative (e.g. due to the consequence of trauma or load-bearing throughout life), and it can involve tendons, joints, ligaments, and bones (Bradshaw et al., 2002).

The broiler growth rate has been found to have a direct relationship with susceptibility to ascites and skeletal disorders (Camacho et al., 2004). Nemati et al. (2017) reported that rapid growth of modern broilers in a relatively short period of time requires a parallel increase in the size or capacity of supply organs, such as those of the cardiovascular and respiratory systems. However, due to the slower development of these organs relative to body growth rate, the capacity to balance body energy is compromised, particularly under extreme environmental conditions, such as cold stress (Shahir et al., 2012; Shinder, 2002). Manipulation of the diet composition and or feed allocation system can have a major effect on the incidence of ascites and skeletal disorders.

Generally, broiler diets could be offered in three forms, Mash, crumble and pellet. Most meat birds are fed crumbled or pelleted diets to achieve maximum growth and feed efficiency (Naderinejad et al., 2017). Feeding mash reduces growth rate (1 to 2 days to market) and reduces mortality and condemnations due to metabolic disease (Baghbanzadeh and Decuypere, 2008). However, this type of feeding programme may not be economically acceptable in all areas and has been demonstrated to increase the incidence of pendulous crops and higher production of inedible parts such as viscera (Kuleile and Molapo, 2019). Broilers that consume pellet feed have frequently been shown to have higher incidences of ascites and skeletal disorders than broilers that consume the same diet in mash form (Bölükbasi et al., 2005). On the same note Farm Animal Welfare Council (FAWC) stated that their Working Group found leg problems of varying degrees of severity on nearly every farm visited (FAWC, 1992). The report stressed that in the worst cases birds were only able to move with great difficulty and such birds were obviously distressed and had problems in reaching food and water. A Danish study in 1999 assessed the prevalence of lameness in a large and representative sample of commercial flocks. This study found that $30.1 \%$ of the birds had gait scores of 3,4 or 5 , which indicate that they are suffering from chronic pain (Sanotra, 1999).

Some of the feasible nutritional strategies such as early age feed or nutrient restriction (qualitative or quantitative) and use of appropriate feed form and light restriction lower the growth rate without compromising the final live weight (Baghbanzadeh and Decuypere, 2008). Optimization of the house temperature and ventilation in cold weather are also beneficial management practices to decrease incidences of ascites, SDS and lameness (Singh et al., 2013, 2018).

The objective of the current study, therefore, was to use nutritional strategy in the form of different broiler feed forms to control the incidences of ascites, SDS and lameness.

\section{MATERIALS AND METHODS}

\section{Ethical approval}

The scientific and ethics committee of the Faculty of Agriculture, National University of Lesotho approved the study protocol.

\section{Study site}

The study was conducted at the National University of Lesotho poultry farm located at $29^{\circ} 28^{\prime} \mathrm{S}$ latitude; $27^{\circ} 44^{\prime} \mathrm{E}$ Longitude (AfriGIS, 2020); at the altitude of $1650 \mathrm{~m}$ a. s. I.

\section{Experimental design}

The experimental design was Completely Randomized Design with two dietary treatments replicated four times. Dietary treatments were made up of two broiler feed forms namely mash and pellets. The two diets had similar nutritive value but differ in structural composition.

\section{Birds housing and management}

One day old mixed-sex Ross 308 chicks $(n=200)$ were obtained from Letsatsi (local agro dealer) on the hatching day. The birds were reared in deep litter floor pens. The chicks were allocated into 8 pens and they were 25 birds per replicate. The room was lit $\mathbf{2 4}$ hours for the first $\mathbf{4 2}$ days. The experimental feeds and water were provided on ad libitum basis during the whole experimental period and all necessary prophylaxis and vaccination requirements for broilers were administered equally.

\section{Data collection}

\section{Production parameters}

Data on production parameters, such as live weight, growth rate, feed intake and feed conversion ratio were collected on weekly basis, while mortality rate, signs of ascites and lameness were recorded on daily basis. Live weight was measured using a platform weighing scale, Feed conversion ratio (FCR) was calculated as feed intake (g) over live weight (g). Feed intake was determined by the difference between feed supplied and leftovers. Growth rate was measured as the final weight minus initial weight divided by number of days. Mortality rate was recorded from 0 weeks 
until the 6 weeks by the following formula: Mortality $\%=$ No. of death birds in a replication/No. of initial birds in a replication $\times 100$.

\section{Disorders parameters}

Data collection started at the beginning of the growing phase up to the end of finishing phase (17 to 42 days) because pellets were too big for consumption by the day-old chicks. Birds were observed on daily basis for the signs of lameness, abnormal gait and those sitting down all the time not able to reach waterers and feeders. United State gaitscoring system was used to measure the prevalence of leg weakness by assessing the walking ability of broilers. Walking ability was scored according to three category as follows; 0(no obvious signs of problems), 1 (obvious signs) and 2(severe signs). Sudden death syndrome was recorded as birds that die without any symptoms of illness and they usually lie on their back with the feet raised. Dead birds were collected daily, weighed, and necropsied for the presence of water accumulation in the abdomen, which was considered as ascites. Any skeletal abnormalities were noted as they were discovered.

\section{Statistical Analyses}

Data collected was analyzed using IBM SPSS (version 20.0) and when the existence of difference between treatment means was declared, Least Significant Difference (LSD) test was employed to detect differences between treatments. The model used was; $Y i j k=\mu+T i+e i j$, where: $Y i j=$ observation or over all response; $\mu=$ the overall mean;

$\mathrm{Ti}=$ the effect of treatments (i.e. forms of feed); eij = random error.

\section{RESULTS AND DISCUSSION}

\section{Production Parameters}

The broiler feed forms had significant $(P<0.05)$ effect on all production parameters (Table 1$)$. Birds that had access to diet in pellet form had significantly $(P<0.05)$ higher feed intake, growth rate, feed conversion ratio, live weight and mortality rate than birds offered diet in a mash form. Feed intake and feed conversion ratio and growth rates results are in agreement with the findings of Kuleile and Molapo (2019), Hasani et al. (2018), Hosseini et al. (2017), Naderinejad et al. (2017), Chehraghi et al. (2013), Dozier et al. (2010), Amerah et al. (2007) who reported that feeding pelleted diets during growing and finishing phases increased broiler feed efficiency. On the contrary, Fasuyi and Odunayo (2015) reported that mash diet resulted in higher feed intake and feed conversion ratio than birds fed pelleted diet. The discrepancy may be due to the size of the pellets which was not suitable for chicks during this growth stage. Broiler mortality rate results are in accordance with the findings of Bricket et al. (2007) and Van Biljon (2006) who reported higher $(\mathrm{P}<0.05)$ mortality in chickens fed the crumble-pellet regimen $(6.57 \%$ at 42 days), compared to chickens on the ground crumbles and pellets ( $4.03 \%$ at 42 days) and all-mash regimen ( $2.85 \%$ at 42 days). They also noted that feeding mash reduced the overall mortality as well as the mortality in every time period, starting at $14 \mathrm{~d}$ of age, in comparison with feeding pellet diets. On the other hand Al-Nasrawi (2016), Moayyedian et al. (2011), Dozier et al. (2010), Norollahi (2008), Scott (2002), Engberg et al. (2002), Nir et al. (1995) stated that different broiler feed forms did not have a significant influence on mortality rate. Ommati et al. (2013) also reported no differences in mortality rate. However, they observed that mortality was highest in pellets fed broilers with $12.7 \%$ while mash fed birds group had $9 \%$. The inconsistency of reports on the effect of feed forms on mortality may be due to the difference in the duration of feeding.

The observed results on production parameters clearly revealed the superiority of pelleted diets to optimize broiler production during growing and finishing phase items of feed intake, growth and high feed efficiency. Pelleted diet offers a complete nutrient package for broilers because it reduces nutrient segregation and feed wastage as compared to mash diet (Ghazi et al., 2012). Broilers fed pelleted diet had high feed intake than birds fed mash diet because pelleted diet has a bigger particle size than mash and therefore it is consumed relatively faster than diet in mash form. Birds consuming diet in mash form spent a lot of time and energy in the act of eating and hence why low feed conversion efficiency. Moran, (1987), Flemming et al. (2002) and Skinner-Noble et al. (2005) indicated that pellet rations increased available dietary energy for live weight gain, which improved feed efficiency by reducing the time spent eating and increasing the time spent resting. The benefits of pellet feeding on broiler performance have been extensively reported and the current work confirms the benefits in terms of higher feed intake, weight gain and feed efficiency but prone to high incidences of metabolic disorders.

\section{Table 1 - The effects of feed form on broiler production}

\begin{tabular}{lcc|cc} 
Parameters & \multicolumn{2}{c|}{ Treatments } & \multicolumn{2}{c}{ Significance } \\
\cline { 2 - 5 } & Mash & Pellets & \multicolumn{2}{c}{ P1 } \\
\hline Feed intake (grams/week) & 769 & 951 & 0.033 & 11.26 \\
Growth rate (grams/day) & 59 & 84 & 0.019 & 9.34 \\
Feed conversion ratio (g/g) & 2.2 & 2.6 & 0.024 & 28.28
\end{tabular}




\begin{tabular}{|lcccc|}
\hline Live weight & 1689 & 2470 & 0.001 & 8.91 \\
Mortality rate & 0.7 & 7.5 & 0.002 & 0.21 \\
\hline $\mathrm{P}<0.05$ = Means differed significantly, $\mathrm{P}^{1=}$ Probability at $5 \%, \mathrm{CV}^{2}=$ Coefficient of variation & & & &
\end{tabular}

\section{Metabolic Disorders Parameters}

The broiler feed forms had significant $(P<0.05)$ difference on ascites and skeletal disorders however, there was no differences $(P>0.05)$ between feed forms on sudden death incidences. The incidence of ascites and skeletal disorders were significantly higher in broilers fed pelleted diet than birds fed mash diet. Similar trend in results were observed for sudden death syndrome where more incidence were observed in birds offered diet in form of pellets. Van Biljon (2006) results concurred with the findings of the current study on incidences of ascites and skeletal disorders who reported significantly higher mortality mainly caused by ascites $(2.11 \%)$ and SDS (1.39\%) in crumble-pellet treatment than in all mash diets. Skeletal disorders incidences were higher in ground crumble-pellet treatment than in group fed all mash diet. A number of researchers also confirmed the findings of the present study that feeding pellets to broilers lead to fast growth rates that in turn resulted in high incidences of ascites and SDS (Hasani et al., 2018; Meshram and Bijoy 2017; Ghazi et al., 2012; Arce-Menocal et al., 2009; Sarvestani et al., 2006; Bölükbasi et al. 2005; Arce et al., 1985). Arce et al. (1985) observed $15 \%$ incidence of ascites in pellets compared to $4 \%$ in mash diets. In the current study broilers fed pellets diet grew significantly faster than birds fed mash and hence the high incidence of ascites and skeletal disorders in these group of birds. Variation in observed results amongst researchers could be as a result of combination of feed form treatment with cold induced treatment, different altitudes, lighting programme, stocking density in rearing house as well as the use of bioenzymes. Researchers also reiterated that skeletal disorders, ascites and SDS are the common cause of economic losses due to mortality and downgrades in fast-growing broiler strains.

\section{Table 2 - The effects of feed form on incidences of ascites, sudden death and skeletal disorders}

\begin{tabular}{|c|c|c|c|c|}
\hline \multirow{2}{*}{ Parameters } & \multicolumn{2}{|c|}{ Treatments } & \multicolumn{2}{|c|}{ Significance } \\
\hline & Mash & Pellets & $\mathbf{P 1}$ & CV2 $^{2}$ \\
\hline Ascites (\%) & 0.75 & 6.25 & 0.033 & 11.26 \\
\hline Sudden death syndrome (SDS) & 0.00 & 1.30 & 0.356 & 28.28 \\
\hline Skeletal disorders & 0.75 & 5.75 & 0.001 & 8.91 \\
\hline
\end{tabular}

\section{CONCLUSION}

The findings of the current study revealed that broiler feed forms had a profound influence on the occurrences of ascites, sudden death syndrome and skeletal disorders whereby feed in the form of mash significantly reduced metabolic disorders in broilers compared to feed in the form of pellets which resulted in significantly high incidences. However, broiler mash diet gave significantly poor growth rates, feed conversion ratio and final live weight. It was concluded that pelleted feeds improved growth rate and feed conversion ratio, albeit by inducing metabolic disorders in broilers. It is recommended that farmers in Lesotho especially those in the highlands should consider feeding their broilers diet in the form of mash during the period of high susceptibility such as winter time. Farmers in the highlands should feed their broilers diet in the form of mash coupled with improved management practices that are known to influence metabolic disorders such as temperature control, oxygen, dust percentage in air, microorganism toxins, nitric oxide metabolism, vitamin $\mathrm{E}$ and selenium supplementation. Future research should evaluate the economic advantage of feeding mash versus pelleted feed through partial budget analysis.

\section{DECLARATIONS}

\section{Acknowledgements}

The authors wish to thank the National University of Lesotho for providing financial support to undertake this study. We also thank Mr Mahlaha for assisting with animal housing and structures needed to house the experimental animals.

\section{Competing interests}

The authors declared that they did not have a conflict of interest with respect to the research.

\section{Author's contribution}

Nchele Kuleile designed the experiment, supervised data collection, analyzed data and compiled the manuscript. Ncheche, Kamoho, Macheli, Jobo and Phororo collected data, conducted post mortem for dead chickens and inserted data in statistical analysis tool. All authors have proof read the final manuscript. 


\section{REFERENCES}

Afolayan M, Abeke FO and Atanda A (2016). Ascites versus sudden death syndrome (sds) in broiler chickens: a review. Journal of Animal Production and Research, 28(2):76-87. ISSN 0189-0514 Google Scholar

Agah MJ, H Norollahi (2008). Effect of feed from and duration time in growing period on broilers performance.International Journal of Poultry Science, 7(11): 1074-1077. http://dx.doi.org/10.3923/ijps.2008.1074.1077

Al-Nasrawi MAM (2016). The impact of different dietary forms (mash, crumble and pellets) on some growth traits and carcass characteristics of broilers. Journal of Animal Health and Production. 4(2): $31-36$. https://doi.org/10.14737/journal.jahp/2016/4.2.31.36

Amini K, Zachar T, Popowich S, Knezacek T, Goodhope B, Willson P, Gomis S. (2015). Association of increased rate of condemnation of broiler carcasses due to hepatic abnormalities with immunosuppressive diseases in the broiler chicken industry in Saskatchewan. Canadian Journal of Veterinary Research, 79(4): 261-267 Google Scholar

Arce-Menocal J, Avila-Gonzalez E, Lopez-Coello C, Garibay-Torres L and Martinez-Lemus LA (2009). Body weight, feed particle size, and ascites incidence revisited. The Journal of Applied Poultry Research, 18(3): 465-471. https://doi.org/10.3382/japr.2008-00095

AriGIS (2020). Map of Lesotho. https://www.afrigis.co.za

Baghbanzadeh A and Decuypere E (2008). Ascites syndrome in broilers: physiological and nutritional perspectives, Avian Pathology, 37(2):117-126, https://doi.org/10.1080/03079450801902062

Bölükbasi SC, Aktas MS and Güzel M (2005). The effect of feed regimen on ascites induced by cold temperatures and growth performance in male broilers. International Journal of Poultry Science, 4(5):326-329. Google Scholar

Bradshaw RH, Kirkden RD and Broom DM (2002). A review of the aetiology and pathology of leg weakness in broilers in relation to welfare. Avian and Poultry Biology Reviews 13:45-103. http://dx.doi.org/10.3184/147020602783698421

Brickett KE, Dahiya JP Classen HL, Gomis S (2007). Influence of dietary nutrient density, feed form, and lighting on growth and meat yield of broiler chickens. Poultry Science, 86: 2172-2181. http://dx.doi.org/10.1093/ps/86.10.2172

Camacho MA, Suarez ME, Herrera JG, Cuca JM and Garcia- Bojalil CM (2004). Effect of age of feed restriction and microelement supplementation to control ascites on production and carcass characteristics of broilers. Poultry Science, 83:526-532. Scholar

Chehraghi M, Zakeri A and Taghinejad-Roudbaneh M (2013). Effect of different feed forms on performance in broiler chickens. European Journal of Experimental Biology. 3: 66-70. ISSN: 2248 -9215 Google Scholar

Dozier WA, Behnke KC, Gehring CK and Branton SL (2010). Effects of feed form on growth performance and processing yields of broiler chickens during a 42-day production period. The Journal of Applied Poultry $\quad$ Research $\quad 19 \quad 219-226$. https://dx.doi.org/10.3382/japr.2010-00156

Engberg RM, Hedemann MS, Jensen BB (2002). The influence of grinding and pelleting of feed on the microbial composition and activity in the digestive tract of broiler chickens. British Poultry Science Journal, 43:569-579. Google Scholar

Farm Animal Welfare Council (1992).Report on the welfare of broiler chickens. Farm Animal Welfare Council. Pp. 6

Fasuyi AO and Odunayo OT (2015). Particulating broiler feeds into forms and sizes for nutritional and economic benefits (part 1). African Journal of Food Science, 9(4):223-229. Google Scholar

Ghazi AMZ, Al-Maktari GA and Amer MM (2012). A comparative effect of mash and pellet feed on broiler performance and Ascites at high altitude (field study). Global Veterinaria Journal. 9 (2): 154-159. http://dx.doi.org/10.5829/idosi.gv.2012.9.2.63156

Hasani A,Bouyeh M,Rahati M, Seidavi A, Makovicky P, Laudadio V and Tufarelli V (2018). Which is the best alternative for ascites syndrome prevention in broiler chickens? Effect of feed form and rearing temperature conditions. Journal of Applied Animal Research, 46(1): 392-396. http://dx.doi.org/10.1080/09712119.2017.1309320

Hosseini SM, Chamani M, Mousavi SN, Hosseini SA and Sadeghi AA (2017). Effects of dietary physical form and dietary inclusion of probiotic and enzyme on growth performance, cellular and humoral immunity, and relative weights of lymphoid organs at early period of broiler chickens fed triticale-based diets. South African Journal of Animal Science, 47(6): 776-784. http://dx.doi.org/10.4314/sajas.v47i6.5

Huchzermeyer FW, Van Der Colf WJ, and Guinane PR (1989). Broiler ascites: increased oxygen demand with cold may explain high winter incidence. Poultry Bulletin September: p474 and p483. Google Scholar

Julian RJ (2005). Production and growth related disorders and other metabolic disease of poultry - a review. Veterinary Journal 169: 350369. Google Scholar

Kuleile N and Molapo S (2019). The influence of feed form on broiler production and gastrointestinal tract development. Online Journal of Animal and Feed Research, 9(1): 38-43. ISSN 2228-7701 Google Scholar

Maxwell M and Robertson G. (1998). UK survey of broiler ascites and sudden death syndrome in 1993. British Poultry Science 39: 203215. Melbourne, Victoria. ISBN 978-1-925629-84-2 (Print) pp 91-97. Google Scholar

Meshram PV and Bijoy F (2017). Managemental and nutritional disease - sudden death syndrome in broilers.International Journal of Science, Environment and Technology, 6(1): 260-266. ISSN 2278-3687. Google Scholar

Moayyedian H, Asasi K, Nazifi S, Hassanzadeh M and Ansari-Lari M (2011). Relationship between venous blood gas parameters,thyroid hormone levels and ascites syndrome in broiler chickens exposed to cold temperature. Iranian Journal of Veterinary Research, 12(1): 31-38. Google Scholar

Naderinejad S, Hassanabadi A, Kermanshah H, Zaefarian F, Abdollahi MR and Ravindran V (2017). Influence of feed form and particle size on the performance and nutrient utilisation of broiler starters fed maize-based diets. Animal Feed Science and Technology, 215: 92-104. https://dx.doi.org/10.1016/j.anifeedsci.2016.02.012

Nemati MH, Shahir MH, Harakinezhad MT, Lotfalhian H (2017). Cold-induced Ascites in broilers: effects of vitamin C and coenzyme Q10. Brazilian Journal of Poultry Science, 19 (3): 537-544. http://dx.doi.org/10.1590/1806-9061-2017-0463

Nicol CJ, Bouwsema J, Caplen G, Davies AC, Hockenhull J, Lambton SL, Lines JA, Mullan S and Weeks C (2017). Farmed Bird Welfare Science Review. Department of Economic Development, Jobs, Transport and Resources. Google Scholar

Nir I, Hillel R, Ptichi I, Shefet G (1995). Effect of particle size on performance 3 grinding pelleting interactions. Poultry Science Journal, 74(5):771-783. http://dx.doi.org/10.3382/ps.0740771 
Ommati MM, Rezvani MR, Atashi H and Akhlaghi A (2013). Effect of physical form of diet and ambient temperature on performance and carcass attributes in broilers. Arch. Geflügelk., 77 (4) 247- 253. ISSN 0003-9098 Google Scholar

Saffar A and Khajali F (2010). Application of meal feeding and skip-a-day feeding with or without probiotics for broiler chickens grown at high-altitude to prevent Ascites mortality. American Journal of Animal and Veterinary Sciences 5 (1): 13-19. ISSN 1557-4555. Google Scholar

Saki AA and Hemati M (2011). Does nutrition help to alleviate sudden death syndrome in broiler chicken? Global Veterinaria, 6 (3): 262 268. ISSN 1992-6197. Google Scholar

Sarvestani TS, Darbiri N, Agah MJ and Norollahi H (2006). Effect of pellet and mash diets with biozyme enzyme on broiler performance. International Journal of Poultry Science. 5:485-490, http://dx.doi.org/10.3923/ijps.2006.485.490

SCAHAW (2000). The welfare of chickens kept for meat production (broilers). Report of the Scientific Committee on Animal Health and Animal Welfare. Adopted 21 March 2000.

Scott TA (2002). Evaluation of lighting programs, diet density, and short-term use of mash as compared to crumbled starter to reduce incidence of sudden death syndrome in broiler chicks to 35 days of age. Canadian Journal of Animal Science, 82: $375-383$. http://dx.doi.org/10.4141/A01-067

Shahir MH, Dilmagani S, Tzschentke B (2012).Early-age cold conditioning of broilers: effects of timing a temperature. British Poultry Science, 53:538-544. Google Scholar

Shinder D, Luger D, Rusal M, Rzepakovsky V, Bresler V, Yahav S (2002). Early age cold conditioning in broiler chickens (Gallus domesticus): thermo tolerance and growth responses. Journal of Thermal Biology, 27:517-523. Google Scholar

Singh PK, Shekhar P and Kumar K (2013).Nutritional and managemental control of ascites syndrome in poultry. Journal of Poultry Farming and Vaccination, 1(1): 076-082 Google Scholar

Singh S, Verma H and Chakraborty D (2018). Ascites Syndrome: a challenge for blooming poultry industry. International Journal of Advances in Agricultural Science and Technology, 5(6):9-15 ISSN: 2348-1358 Google Scholar

Van Biljon NJ (2006). The effect of feed processing and feed texture on bodyweight, feed conversion and mortality in male broilers. Abstract. University of Pretoria MSc Thesis. http://hdl.handle.net/2263/23371 